\title{
Surface Engineering for Extreme Conditions
}

\author{
SRINIVASA RAO BAKSHI ${ }^{1}$ and SANDIP P. HARIMKAR ${ }^{2,3}$ \\ 1.-Department of Metallurgical and Materials Engineering, Indian Institute of Technology \\ Madras, Chennai, India. 2.-School of Mechanical and Aerospace Engineering, Oklahoma State \\ University, Stillwater, OK, USA. 3.—e-mail: sandip.harimkar@okstate.edu
}

Developments in technology and processes today require several components to work under extreme conditions of temperature, corrosive environment, and mechanical/tribological stresses. Such conditions are abundantly found in automotive, aerospace, heavy machinery, nuclear, and thermal power industries, to name a few. The materials capable of performing under such conditions are either expensive or deficient in other properties, or they lack good formability. Thus, surface engineering by means of coatings of special materials on the existing components is a highly practiced method. The number of different coatings applied in an aeroengine is testimony for the multifunctionality that can be achieved by the use of coatings. The use of exotic or expensive materials in the form of coatings reduced the overall cost of the components. An increase in the service life of components can also justify the cost of expensive coating materials. Coatings are regularly applied on components by a variety of techniques such as weld cladding, thermal spraying, and electrochemical techniques, to name a few. Apart from these techniques, the surfaces can also be modified chemically to obtain special functionalities. This special issue of JOM was proposed to highlight the recent developments in the processing and characterization of coatings for components serving under extreme conditions.

As protective coatings provide the main functionality in the systems, adequate monitoring of the condition of the coatings in service is necessary to avoid catastrophic failures. The article by Manero et al., "Monitoring Local Strain in a Thermal Barrier Coating System Under Thermal Mechanical Gas Turbine Operating Conditions," presents the results of an extensive collaborative effort to characterize the mechanical behavior of the multilayer coatings during a representative service loading. The article discusses the development of advanced

Sandip Harimkar is the guest editor for the Surface Engineering Committee of the TMS Materials Processing \& Manufacturing Division, and coordinator of the topic Surface Engineering for Extreme Conditions in this issue. nondestructive technique based on synchrotron $\mathrm{x}$-ray diffraction for in situ strain measurements for the investigation of real-time material response and damage mechanics. The experimental results obtained are likely to be very useful for the computational efforts to advance the understanding of the damage mechanisms in thermal barrier coatings.

The article by Vackel et al., "Structurally Integrated, Damage Tolerant, Thermal Spray Coatings," presents an excellent overview of the materials, process, microstructure, and performance-related aspects of the thermal spray coatings. The article also highlights the role of processinduced residual stresses on the performance of the thermal spray coatings. The authors performed integrated studies on several hardfacing compositions subjected to a range of processing conditions to establish process-structure-property-performance correlations for several performance conditions such as wear, fatigue, and corrosion. These processstructure-property-performance correlations are likely to guide the industry to develop better damage tolerant coatings for a range of applications.

The article by Ananthapadmanabhan et al., "Plasma-Sprayed Ceramic Coatings for Barrier Applications Against Molten Uranium Corrosion," discusses the difficulties in handling molten uranium alloys in the nuclear industry. Although uranium has a low melting point of $1132^{\circ} \mathrm{C}$, the article shows that its reactions with ceramic coatings such as alumina and zirconia render these coatings unsuitable for protection against hot corrosion. The article provides a summary of the recent efforts toward the development of plasma-sprayed yttria coatings for protection against molten uranium and shows that yttria coatings are best suited for handling molten uranium because of their inert behavior. The article shows that plasma spraying can be an effective method for the processing of good quality (crack-free) yttria coatings to protect against molten uranium.

While thermal spray coatings are robust and exclusively applicable for larger parts, thin coating 
techniques are available for relatively smaller parts for machining and tribological applications. Physical vapor deposition (PVD) and chemical vapor deposition (CVD) coatings fall into this latter category. The article by Dumpala et al., "Engineered Chemical Vapor Deposition Diamond Coatings for Machining and Tribological Applications," presents an overview of the processing, microstructure, and performance characteristics of the CVD diamond coatings deposited on cemented tungsten carbide substrates. The article discusses the role of cemented carbide substrate grade selection, substrate pretreatment, crystallinity of the coating, coating architecture, and interfacial properties on the performance of the coatings in harsh and highly abrasive conditions. The article shows that multilayer composite coatings incorporating both nanocrystalline and microcrystalline diamond layers improve the interfacial integrity and performance of the CVD diamond coatings.

Significant research efforts are being made toward the development of bulk metallic glasses for structural applications. These alloys are very expensive and difficult to fabricate in bulk forms. With these difficulties, the bulk metallic glasses seem better suited for use as coatings than general bulk structural materials. The paper by Ji et al., "High-Temperature Sliding Wear Behavior of Zr-Based Bulk Amorphous Alloys," presents the results of high-temperature dry sliding wear studies carried out on $\mathrm{Zr}_{64.13} \mathrm{Cu}_{15.75} \mathrm{Ni}_{10.12} \mathrm{Al}_{10}$ glass and AISI H13 steel. It is shown that the wear rate of Zr-based bulk metallic glass was approximately an order of magnitude lower than that of AISI H13 under similar sliding wear conditions at room temperature. At higher temperatures, several effects such as surface oxidation, viscous flow, protective layer formation, and abrasive wear depending on the wear testing temperature influence the wear characteristics of bulk metallic glass.
We thank the members of the TMS Surface Engineering Committee for providing the ideas leading to the topic selection for this feature issue. We also thank the authors for contributing their best works to be published in this issue. We hope that the surface engineering community will find the articles published in this issue interesting, and we look forward to working with you to set the future programming activities of the Surface Engineering Committee.

The following articles being published under the topic of Surface Engineering for Extreme Conditions provide excellent details and research on the subject. To download any of the papers, follow the URL http://ink.springer.com/journal/11837/67/7/page/1 to the table of contents page for the July 2015 issue (vol. 67, no. 7).

- "Monitoring Local Strain in a Thermal Barrier Coating System Under Thermal Mechanical Gas Turbine Operating Conditions," by Albert Manero II, Stephen Sofronsky, Kevin Knipe, Carla Meid, Janine Wischek, John Okasinski, Jonathan Almer, Anette M. Karlsson, Seetha Raghavan, and Marion Bartsch.

- "Structurally Integrated, Damage Tolerant, Thermal Spray Coatings," by Andrew Vackel, Gopal Dwivedi, and Sanjay Sampath.

- "Plasma-Sprayed Ceramic Coatings for Barrier Applications Against Molten Uranium Corrosion," by P.V. Ananthapadmanabhan, Y. Chakravarthy, Vandana Chaturvedi, T.K. Thiyagarajan, and A. Pragatheeswarana.

- "Engineered Chemical Vapor Deposition Diamond Coatings for Machining and Tribological Applications," by Ravikumar Dumpala, Maneesh Chandran, and M.S. Ramachandra Rao.

- "High-Temperature Sliding Wear Behavior of Zr-Based Bulk Amorphous Alloys," by Xiulin Ji, S. Habib Alavi, and Sandip P. Harimkar. 